\title{
Téoros
}

Revue de recherche en tourisme

\section{Le voyage et le repas}

\section{Alain Beaulieu}

Volume 3, numéro 3, novembre 1984

Cuisine québécoise, restauration et tourisme : vers une synergie féconde

URI : https://id.erudit.org/iderudit/1080773ar

DOI : https://doi.org/10.7202/1080773ar

Aller au sommaire du numéro

Éditeur(s)

Université du Québec à Montréal

ISSN

0712-8657 (imprimé)

1923-2705 (numérique)

Découvrir la revue

Citer cet article

Beaulieu, A. (1984). Le voyage et le repas. Téoros, 3(3), 2-9.

https://doi.org/10.7202/1080773ar

Ce document est protégé par la loi sur le droit d'auteur. L'utilisation des services d'Érudit (y compris la reproduction) est assujettie à sa politique d'utilisation que vous pouvez consulter en ligne.

https://apropos.erudit.org/fr/usagers/politique-dutilisation/
Cet article est diffusé et préservé par Érudit.

Érudit est un consortium interuniversitaire sans but lucratif composé de l’Université de Montréal, l'Université Laval et l'Université du Québec à Montréal. Il a pour mission la promotion et la valorisation de la recherche. https://www.erudit.org/fr/ 


\title{
Le voyage et le repas
}

\author{
par Alain Beaulieu*
}

"Entre civilisations bien assises ou a demi-assises, un échange continu de biens culturels est la regle. Doù des vovages, des mouvements: tout est emporté a la fois, aussi bien les hommes. eux surtout, que les animaux ou les plantes domestiques, que les techniques, les façons de penser, de voir, d'agir... ou que les plus modestes recetres de cuisine.

Fernand Braudel ${ }^{10}$

Cet article se propose de parler de tourisme et de gastronomie; de les mettre en relation dialectique. II s'agit de deux activités ludiques, c'est-â-dire que l'homme s'y adonne non pas par nécessitế, mais par plaisir. A moins que le plaisir ne soit une nécessité.

"C'est dans la joie et non dans la peine que / homme a trouvé son esprit. La conquette du superflu donne une excitation plus grande que la conquête du nécessaire. L'homme est une création du désir. non une création du besoin.

Gaston Bachelard ${ }^{(2)}$

Mais ces deux activités ludiques ont un caractère différent. Par exemple, l'une est un voyage intérieur, et l'autre, un voyage extérieur. II y a d'autres différences. Ainsi, l'une et l'autre placent l'homme dans un rapport différent avec la Nature, d'une part, et avec la Culture, d'autre part.

II s'agit de savoir si ces deux activités peuvent être mises en rapport complémentaire, pour le bénéfice du tourisme et du touriste. Le tourisme, qui cherche toujours à diversifier ses produits, peut-il intégrer la gastronomie dans ses ressources? Le touriste peut-il ajouter à ses plaisir celui de la gastronomie?

Ce n'est pas une question futile puisqu'il s'agit de développement touristique, donc d'une question économique. II s'agit aussi d'une question de développement culturel.

-Alain Beaulieu est professeur a l'Institut de tourisme et d'hótellerie du Québec.
Mais pour y répondre, il faut mettre cette question dans un contenant plus profond qu'il $n^{\prime} y$ parait, car les ingredients sont nombreux et risquent de déborder. II faut bien agiter aussi, afin que les grumeaux se dissolvent.

Nous nous proposons de le faire. Ainsi, remonterons à la surface, et successivement, pour le tourisme d'abord et la gastronomie ensuite, des considérations plus profondes: mythiques, anthropologiques, historiques, biopsychologiques. Elles aideront, espérons-nous, à mieux comprendre ce qui fait difficulté à la surface, au niveau technique, que nous $n^{\prime \prime}$ aborderons pas ici. Elles pourront donner des indices de solution, si le tourisme et le touriste désirent toujours franchir les frontières du royaume de Gaster.

La route est sinueuse et tout voyage comporte des risques. Ne vous lassez pas; laissez-vous entrainer. Mais regardez bien, il y a des choses à voir. Puissiez-vous pareillement goûter à tout.

Pensez seulement qu'autrefois, avant qu'on en ait fait le tour, le monde était percu, conçu comme une vaste assiette. Ce qui fait qu'en ce temps-là, du moins, le voyage c'était tout un repas!

\section{Le combat de Caïn}

ua vie est une sorte de deroulement des actes de l'homme, actes dont le plus grand nombre est suscité par le besoin et la préparation de la nourriture.,

Plutarque ${ }^{|3|}$

La main, la gaule et le gourdin

Puisque ces deux activités ludiques que sont le tourisme et la gastronomie mettent, chacun à sa manière, l'homme en rapport avec la Nature et avec la Culture, considé. rons un instant et pour lui-même ce rapport fondamental, pour mieux comprendre par la suite l'incidence de ces deux activités dans ce rapport.
L'homme se démarque des autres espèces vivantes dans ses rapports avec la Nature. D'abord, parce qu'ill a eu d'elle une conscience, qui, de confuse qu'elle était, a évoluế, s'est éclaircie et s'est précisée. Voilá une premiere distance. Davantage que pour les autres especes, la Nature était menaçante pour ce fragile néotène et le dominait absolument. La préhistoire de l'homme, c'est l'histoire de son combat inégal contre ce géant hostile et meurtrier. Les mythes et les légendes qui sont les premiers balbutiement des civilisations humaines, témoignent largement de cette guerre lente sur tous les fronts et la gardent en mémoire.

Pour combattre, l'homme a dû fabriquer des outils. II a prolongé ses membres, multipliế sa force, augmenté sa dextérité par ses premiers outils avec lesquels il prenait. puisait, cueillait, frappait, fendait, coupait, rappait, attrapait. Et dans ce combat de patience et de ruse, il a réussi, peu à peu, â faire servir ả son avantage les implacables lois qui définissent la Nature. Il a transformé la Nature. Voilà une deuxième distance.

L'homme établit donc avec la nature un rapport de distanciation: il l'appréhende, ill la regarde, il la connaît, il la transforme. Dominé par elle, il a fini par la dominer. Menacé, il est devenu lui-męme menaçant pour elle. Cette distanciation avec la Nature, c'est ce qui fait la Culture de I'homme. En ce sens Nature et Culture se distinguent et s'opposent. Et l'homme est beaucoup plus un être de culture qu'un etre de nature. Il puise dans la nature, mais tout ce qu'il fait est culture.

"Dans /'acte alimentaire, tout a la fois nous nous affrontons avec le reste de la nature et nous communions avec elle. $L a$, nous sommes a l'évidence partie de cette nature, mais dans cet acte alimentaire même, nous nous différencions du reste du monde vivant. Nous nous en differencions par les facons que nous avons de préparer et de consommer les aliments que notre maîtrise de la nature a 
permis de produire. Nous nous en differencions surtout par la part de réve et par les symboles que nous avons mis dans notre alimentation.

Jacques Barraud ${ }^{|4|}$

\section{Le geste et la parole}

Ainsi, les transformations que I"homme opere sur la Nature sont de deux ordres: concrètes, I'homme et ses outils; abstraites, l'homme et son imaginaire: I"homme pense la Nature, il l'imagine, il l'interprète. Ces deux types de transformation sont en relation constante et dynamique, en relation dialectique; ils s'influencent mutuellement et evoluent parallèlement. Entre ces deux transformations, une troisième qui les unit intimement: la transformation verbale. L'homme dit les choses et il les communique. L'homo sapiens est a la fois une homme qui pense, qui fabrique et qui parle. Le résultat qui découle de ces trois ordres d'activité font les modes de vie de I'homme, ses cultures, ses civilisatins. Leur évolution constitue I'histoire. L'homme génère donc ainsi des formes de vie, des systèmes de formes, des codes de comportement. Tout ce qu'il fait est formel et codé.

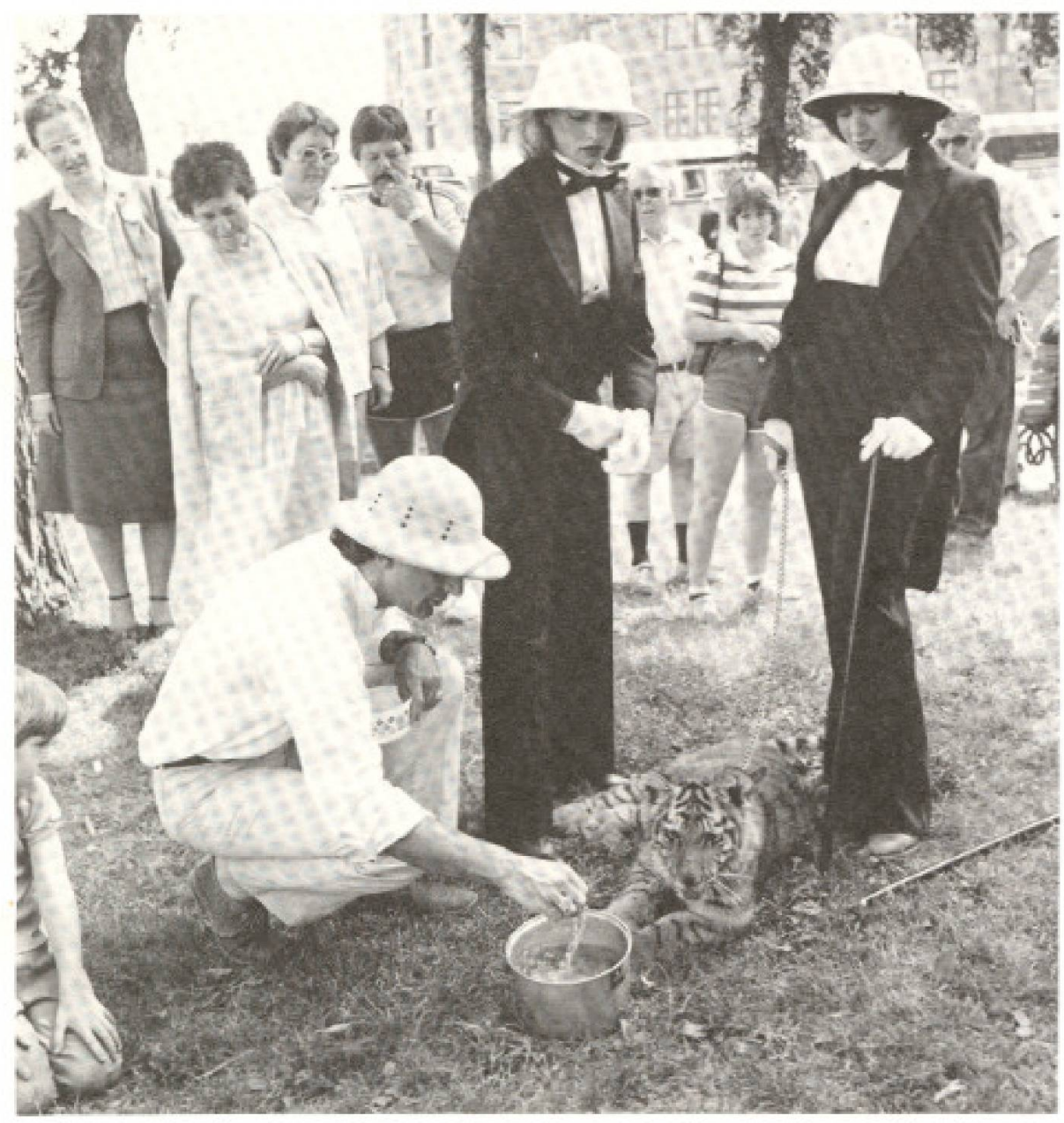

L'homme est beaucoup plus un être de culture qu'un être de nature. II puise dans la nature mais tout ce qu'il fait est culture.
"Les principes alimentaires sont des principes culturels: I'homme choisit, prépare et ingère les aliments en respectant les règles dictées par la société a laquelle ì appartient.,

Frédéric Lange ${ }^{15}$

\section{Le feu, la roue, la chaîne et le four}

L'homme est un être vivant, adroit, habile, ingénieur. Il est industrieux. Les outils qu'il invente et qu'il met au point sont le résultat d'une rencontre réflexive entre la Nature et son esprit. Ce savoir-faire a augmente, s'est démultiplié, s'est accumulé. Ses inventions et ses techniques ont convergé. II a fini par créer l'Industrie et son frère jumeau, le Commerce. $\mathrm{Et}_{\text {r }}$ au point de convergence historique de cette évolution industrieuse, a éclaté, récemment, le phénomeme de l'industrialisation, un séisme qui a secoué violemment les cultures traditionnelles, les manières de penser et de faire, les modes de vie. Les outils sont devenus des machines-outils, les ateliers des usines et les artisans des ouvriers. Les produits ne sont plus fabriqués mais ausinésm et leurs quantités sont devenues aindustriellesw.
"Quand on jette un rapide coup d'oeil sur I'alimentation actuelle, il semble qu'il ne reste rien des principes que l'on peut dégager de l'histoire alimentaire: le monde observé paraît neuf et comme reconstruit après qu'un violent déluge leût dévasté.,

Frédéric Lange ${ }^{(6)}$

Ce bouleversement historique a changé les rapports de l'homme avec la Nature. Non seulement la transforme-t-il et partant la domine-t-il, mais encore il la menace, et dangereusement. De plus, il s'en éloigne. La distanciation s'est accentuee.

Ce bouleversement a aussi changé les rapports de I'homme avec la Culture: il ne s'agit plus d'un rapport individuel, communautaire ou collectif, mais un rapport de masse. A une masse de produits correspond une masse de consommateurs, les uns usinés, standardisés par les industries de transformation, les autres conditionnes par les industries de consommation. Les uns et les autres appelés à se consumer mutuellement sous l'effet des fermenta. tions ardentes du Commerce. C'est une nouvelle culture qui s'est installée avec laquelle l'homme n'a plus que des rapports médiatisés. Les techniques industrielles et commerciales de transformation, de consommation et de communication ont fait que les cultures locales, régionales, nationales mème ont été dominées, radiées par une Culture normalisée, standardisée, mondialisée, universalisée. Le monde est devenu un gros village.

wll y a un flottement géneral, une crise des codes et des représentations alimentaires qu traduit une crise plus generale de la culture et de la civilisation et qui laisse place a une crise bio-culturelle de Ialimentations.

Claude Fischler ${ }^{[7]}$

\section{La tête, le capital et le logiciel}

Dans les activités humaines d'aujourd'hui, dans les modes de vie, rien n'échappe ă l'emprise de l'Industrie et du Commerce qui ont le bras long et le cerveau articulé. $\mathrm{Ni}$ aux médias, leur progéniture, qui ont le verbe haut et persuasif. Ils ont inventé des concepts, mis au point des techniqus, élaboré des langages: gestion, planification, rationalisation, capitalisation, amortissement, rendement, rentabilité, productivité, mise en marché, publicite. Ils ont leurs capitaux humains et monétaires, leurs penseurs, chercheurs, concepteurs, techniciens, technocrates. Ils ont leur hauts et bas fonctionnaires, leur puissant lobbying. leurs succursales multiples. Des complexes industriels et des multinationales existent dans tous les secteurs de l'extraction, de la transformation, des services et de la communication: l'agro-alimentaire, l'éducation, le tourisme, la construction, le 
transport, la restauration, la forêt, les publications, la finance, I'hôtellerie, la téléphonie, les mines, I'hôpital, les ordinateurs, la télévision. Nous avons affaire à la petite, moyenne, grande ou gigantesque entreprises. Elles se ressemblent toutes et les grandes contiennent les petites comme des poupées gigognes.

Voilà quand, comment et en quoi les rapports de l'homme avec la Nature et avec la Culture ont changé et pourquoi l'homme d'aujourd'hui ne peut plus être l'homme d'hier. C'est un homme nouveau, dans une culture nouvelle, et qui s'est éloigné à une vitesse et une distance vertigineuse des hommes et des cultures d'hier, depuis ce wiolent délugen, cette grande rupture de I'industrialisation.

Ce que la culture d'aujourd'hui a hérité des cultures d'autrefois sort de l'usage quotidien pour être relégué à des activités ludiques de reconnaissance et de remémorisation, a un tourisme et à une gastronomie achroniques.

Ne nous faites pas renaître dans les époques révolues, nous y mourrions en naissant, tués par des odeurs, des saveurs et des malheurs dont nous n'avons pas idée aujourd'hui. Ne faites pas apparaître nos. ancêtres ả notre époque, ils blanchiraient de peur, de vertige et de froid au premier contact de notre culture dominée par l'éclat du verre, le poli du métal, la frigide incandescence électrique, la vitesse, la hauteur et la qualité.

\section{Le voyage d'Ulysse}

Nous n'avons pas assez des trop brèves considérations qui précèdent pour comprendre pourquoi et jusqu'à quel point le touriste d'aujourd'hui n'est plus le voyageur d'autrefois. S'il est encore tourmenté par la jouissance fiévreuse d'obéir â la pulsion nomade, par le désir de la métempsycose. par la curiosité lancinante de la différence, si ces motifs persistent encore, ils sont comme retenus à l'état archéologique. Parce que ce voyageur est de nos jours astucieusement manipulé par les industries dont il achète les produits: le tourisme, l'hôtellerie, la restauration et le transport. Parce que le voyage est lui-meme un produit savamment ausinén.

Qu'il en soit ainsi relève de la culture industrielle d'aujourd'hui. Mais avant d'analyser à cet égard l'aculturation actuelle de cette activité, retrouvons la nature de l'archétype du voyage et du voyageur qui dort en nous, d'un sommeil agité.

\section{Une rupture, un risque, une initiation}

Le voyage est une rupture. La nécessité de rompre est une réalité psycho- physiologique et psycho-sociale qui a été fortement représentée dans les mythes et légendes de toutes les cultures et qui a été fortement codée dans toutes les civilisations. Rupture du cordon ombilical, familial, conjugal, social, national et vital. Voilâ le prix dela saine évolution de chacun: rompre.

Il y a en nous une injonction de voyage qui vient d'une part de la lassitude qui nous gagne à vivre dans un univers devenu trop familier, et d'autre part d'une curiosité envahissante à l'égard de ce qui existe derrière la forêt, au-delà de la montagne, au bout du fleuve, par delà la mer. L'histoire de l'Occident, ses aventures et ses conquêtes, s'expliquent par ces deux pulsions dont le mythe est représenté par Ulysse s'arrachant de Pénélope pour franchir les mers et courir les mondes.

Le voyage est une aventure, un risque. Voilà une autre réalité qui fait étinceler l'épée du courage et réveiller le serpent de l'angoisse. C'est le risque du dépaysement, celui de perdre son pays, c'est-à-dire de voir ses sens et ses signes familiers vasciller, basculer dans un monde où l'on peut perdre pied, se perdre tout entier.

Le voyage est une initiation, une initiation à l'Autre, au Monde. C'est la poursuite de I'Énigme, la recherche de l'Oracle, l'épreuve du Labyrinthe. C'est le passage aux Enfers et la première confrontation avec la Mort. Dis-moi ton nom, gardien des portes de Thèbes! - Sphinx je suis,, et je foudroie!

\section{Un aventurier, un explorateur, un chercheur}

Le voyageur, le atéoross est un aventurier en ce qu'il sort d'un royaume qui lui est familier, où chacun a sa place fixée par la culture qui l'a vu naittre. II entre dans un autre royaume de signes qui lui sont plus ou moins étrangers selon la distance culturelle que son voyage lui aura fait parcourir. Le voyageur tente l'aventure parce que l'aventure le tente.

"Que de difficultés en effet je prévois! que d'habitudes d'esprit j'aurai à changerl que de souvenirs charmants je devrai arracher de mon coeur! J'essajerai, mais je ne suis pas sûr de moin.

Ernest Renan ${ }^{\text {is }}$

Le atéorosw est un explorateur qui cherche d'autres signes de la vie que ceux dont il a l'habitude, Oủ sont les pays perdus, les îles enchanteresses, les fruits fabuleux, les animaux monstrueux, les arbres géants, les plus hautes montagnes, les plus abyssales crevasses, les plus obscures cavernes, le plus bleu des climats, les plus sombres forêts? Dis-moi l'effet des échos et le bruit des vagues| Quelle est la vérité des contes et $y$ a-t-il un autre Dieu?
Besoin d'être mystifié, initié, démystifié, le voyageur cherche dans une autre nature. dans une autre culture la réponse ả sa quête fondamentale. II veut s'en aller, mais il veut revenir, muet, les yeux chargés de mystère et son perroquet sur l'épaule.

"Heureux qui comme U/ysse a fait un beau voyage, Ou comme celui-lá qui conquit la toison, Et puis est retourné plein d'usage et raison, Vivre entre ses parents le reste de son ageln

Joachim Du Bellay ${ }^{19 \mid}$

\section{La pérennité d'un mythe}

Ce beau voyage et ce beau voyageur ne sont plus, Ulysse est mort. Homẻre est aveugle et l'Odyssée n'est plus qu'une légende méconnue. Mais le mythe a servi abondamment et merveilleusement la littérature qui s'en est enrichie.

II continue de stimuler les fantasmes et les rêves du voyageur solitaire, de l'explorateur aventureux qui court encore le monde d'aujourd'hui. Celui qui prend la relève d'Ulysse assume volontiers les risques de la rupture qu'il a cherchée en décidant de partir, de faire le saut de l'étrange. Ce voyageur fuit le tourisme dont il n'a que faire. Son voyage est un voyage antique. Le voyage d'Ulysse.

\section{Le voyage d'Urien}

\section{La petite diligence}

II peut rester des traces de la légende dans le tourisme d'aujourd'hui, mais elles sont bien effacées. En réalité, l'industrie du tourisme a d'autres racines qui sont plus récentes. Dans les familles aisées de l'Europe du XVIlle et du XIXe siécles, il était fortement encouragé que les jeunes gens complètent leur formation par un voyage initiatique et culturel, dans les hauts lieux de la culture occidentale. II y avait le Petit Tour, de trois a six mois, dans les grandes capitales. II y avait le Grand Tour qui menait aux confins de l'Europe: Andalousie, Afrique du Nord, Arabie, Asie mineure, Turquie, Grèce, etc. II y avait dans ces voyages une part de risques et d'inconfort liée aux aléas de la route, aux conditions de transport et d'hébergement, à la fortune de la table. II y avait des mésaventures. Mais il y avait aussi la possibilité et le temps qu'il faut pour prendre contact avec les autochtones, vivre avec eux, manger comme eux, parler comme eux, méditer devant les monuments du passé, écrire une prière sur l'Acropole. Cette fièvre du voyage a sévi d'abord chez les Anglais pour qui l'horizon s'arrétait â la mer. C'est dans leur manque qu'est apparu pour la première fois le mot wtourists (vers 1800) qui désignait ces adeptes du petit ou du grand tour et atourismm (vers 1811) pour désigner cette activité mème. 
Mais ce qui fut jadis accessible et significatif à quelques-uns, les thappy feww: jeunes aventuriers, braves marins, valeureux guerriers, pieux pélerins, riches marchands, gens de robe, savants universitaires et fortunés humanistes, est maintenant possible au plus grand nombre: les touristes. Aussi, le tourisme a-t-il changé de nature et de fonction. Encore coutteux, il l'est moins qu'avant, et plus de gens qu'avant ont les movens de le pratiquer. II est moins aventureux aussi, et plus sécuritaire. Mais un autre danger le guette.

\section{Le morse et le taureau}

Après la génération du tourisme des diligences et du bateau à voile est venue celle du chemin de fer et du bateau à vapeur, fils ainés de l'Industrie, enfants géants du Charbon et de l'Acier.

Sur le taureau de fer qui fume, souffle et beugle

Lhomme a montêt trop tôt. Nul ne connaît encor

Quels orages en lui porte ce rude aveugle.

Et le gai voyageur hi hre son trésor:

Adieu voyages lents, bruits lointains quion écoute

Les rires du passant, les retards de lessieu,

Les detours imprévus des pentes variées.

Un ami rencontre, les heures oubliees L'espoir d'arriver tard dans un sauvage hieu.

La distance et le temps sont vaincus.

$$
\text { Alfred de Vigny }{ }^{100 \mid}
$$

Ce témoignage inquiet du poète sonne comme un glas. Avec lindustrialisation qui vient de naître, le passé a basculé brusquement et l'avenir qui suit est angoissant. Nous sommes en 1842! Quand le ventre de ces taureaux fumants se vide aux quais des gares et des ports, il en sort de nouveaux voyageurs. Ce ne sont plus des individus qui arrivent mais des groupes. Et quand ils arrivent, ils déferlent. Ils veulent boire, manger, dormir et voir. Ils repartirons, mais ills seront remplacés, demain, dans le mẻme brouhaha! II faut donc s'organiser. Cela se fit de plus en plus, de mieux en mieux. On accomoda les installations hóteliẻres, restauratrices et touristiques. Cette accomodation donna naissance à de nouvelles industries; le tourisme, l'hötellerie et la restauration. Et le voyageur d'autrefois devint un touriste patenté.

Les progrès de l'industrie et de la technique dans le domaine des moyens de transport et ceux d'un capitalisme inépuisablement ingénieux à créer des besoins, à les exciter par la publicité, a en organiser et administrer la satisfaction, ont collectivisé le voyage et en ont fait, sur une grande échelle, matière à profit.

"Le vovage est devenu un phénomène de masse: il a pris forme de machine et de systemen.

Jean Cassou $(11)$

\section{L'oeil du troupeau}

Le tourisme est ainsi devenu une industrie du usight-seeings qui, avec d'autres (cinéma, télévision), privilégie la vue, ce sens par excellence du XXe siècle. Géante, tentaculaire, multinationale, elle a conquis pour plusieurs pays la premiere ou la deuxieme place des industries a haut rendement économique. Les régions, les pays bénéficient largement des profits qu'elle tire des lieux qu'elle fait visiter.

Elle a industrialisé d'abord les circuits touristiques des premières générations de touristes, c'est-à-dire qu'elle a aménagé et rentabilisé les lieux touristiques célebres: ceux de grands monuments architecturaux des civilisations anciennes Ipyramides, colisées, aqueducs, cathédrales, forteresses, tours, jardins, etc.); ceux des stations de vacances alpines ou balnéaires; ceux des sites pittoresques naturels ou des curiosités urbaines. Ces lieux sont offerts en spectacle ả des masses de touristes qui y trouvent parkings, kiosques, guides, horaires, affiches, dépliants, équipement audiovisuel, sanitaire, securitaire. Des foules y circulent sagement, à la file indienne. On $y$ prend des photos ou on $y$ achete celles qu'on n'a pas pu prendre.

En multipliant sa clientele a qui elle fait regarder, à qui elle donne à voir, elle a multiplié ses ressources, en s'implantant au coeur des villes ou en banlieue, en campagne ou en forêt, à la montagne ou à la mer.

Elle promene ses milliards de clients partout oủ il y a quelque chose à voir, un climat á connaitre, un plaisir à goủter. Elle les étend au soleil, les baigne dans la mer, leur fait respirer l'air de la montagne, leur fait entendre l'échó des cavernes, leur fait palper la frailcheur des forèts, les endort sous les brises de la nuit.

Elle les grise de stimulations sportives intenses, de trépignations urbaines excitantes, diurnes ou noctambulesques, et leur fait passer en revue les nefs d'églises ou les salles de musée.

C'est une industrie bien rodée, qui a établi son empire partout en exploitant jusqu'au seuil de rentabilité le wlithomen. l'uhydrómes ou l'wanthropòmes, c'est-àdire tous les lieux de la surface terrestre rentables sur le plan touristique.

"Et ceci, soit que les vovageurs entrent, des le depart, dans le systeme et accom phissent tout le voyage prévu et ordonné en fasant partie d'un groupe, soit que. partis par leur propres movens, en famille ou en petite compagnie, ou meme tout seu/s, individuellement, is tombert fatalement, dans une contrée touristiquement exploitée et où, bon gré mal gré, is doivent se soumettre aux conduites du tourisme. Partis avec une illusoire pré. tention au comportement personnel, ces vovageurs finissent par accepter les con. ditions que leur impose la mise en coupe réglée de /'endroit où ils sont parvenus et éprowvent a leur tour les delices du consentement et de la passivites.

Jean Cassou $(12)$

Cette activité ludique ne se définit plus par son humanisme, comme c'etait le cas autrefois, mais par des critères qui relèvent de l'Industrie et du Commerce. Son développement fabuleux et son gigantisme ont favorisé d'autres industries auxiliaires qui vont appliquer les mémes lois mercantiles de profits et de rentabilite.

\section{Luxe, calme et volupté}

Tous les voyageurs ne sont pas forcément des touristes, mais tous les touristes sont des voyageurs. En se déployant sur la surface du globe, l'industrie du tourisme et l'industrie du transport a permis à l'héber: gement un essor prodigieux qui vit main. tenant, en proportion importante, des retombées économiques de l'animation touristique universelle.

L'hébergement n'a pas tardè. à l'instar des autres activités économiques, à s'industrialiser et à devenir une industrie lourde en ce qu'elle nécessite d'énormes déboursés d'investissement. Aussi, sa gestion est-elle très complexe et très contrôlée, car la rentabilité est l'implacable loi de son existence. Et cette rentabilité est fragile, dépendant constamment des fluctuations de l'activité touristique.

Mais c'est une industrie malgré tout solide qui a mis en marché des produits hautement sophistiqués, du moins pour les hôtels de grande classe commerciale qui forment un réseau puissant et prestigieux à travers le monde.

Le produit principal de l'hótel, c'est le confort. Avec lui vient le luxe, l'atmosphère. la détente. Chacun des lieux qui font I'hôtel est un produit fort étudié avec des standards et un standing auxquels auront travaillé concepteurs, architecteurs, décorateurs et divers autres spécialistes. Chaque hôte rivalise d'ingéniosité et d'imagination pour charmer les nomades et s'accaparer leur clientale. C'est ainsi que le confort a trouvé dans I'hôtel toutes sortes de lieux où se loger, et le tourisme y est on ne peut plus à l'abri des malaises et très loin du pays dans lequel il prétend pourtant voyager. 
La chambre d'abord. Le touriste y retrouve son intimité, mais dans le luxe: lits grand format et orthopédiques, couvertures et draps de qualité, couvre-lits de nobles tissus, moquette, fauteuils lourds, lampes ouvragées, commode et table de chevets de haut design ou de bois précieux, téléphone, radio, télévision, réfrigérateur à boisson, climatisation, grande baie vitrée, rideaux, tentures. Tout cela dans une harmonie des couleurs, des tissus, des bois, du papier-peint, des cadres décoratifs, du design du mobilier.

La salle de bains: attenante à la chambre, elle est de céramique, de miroir et de porcelaine. Eclairage abondant, serviettes moelleuses, savons fins et scellés, descente de bains, verres stérilisés. Eau chaude et froide, bain et douche, lavabo, toilette et bidet.

Les salles communes: hall, salons, bars, salles à manger, terrasses, piscines, boutiques. Tous lieux feutrés, discrets, décorés avec recherche, luxe et exotisme qui font que chacun d'eux est en soi un lieu touristique rappelant au voyageur son statut privilégié, multipliant pour lui les mille et un plaisirs d'être mollement ailleurs que chez lui.

Les services, ils sont de tous ordres: accueil, réception, information, repas, soins personnels, blanchissage, polissage, banque, infirmerie, etc. Ils sont dispensés avec courtoisie et célérité.

Le touriste est un client et le client est roi, et, pour son intimité, mieux logé qu'á Versailles.

"La, tout $n$ 'est qu'ordre et beauté.

Luxe, calme et volupté,

Charles Baudelaire ${ }^{(13)}$

\section{Le pain, le vin et le coq au vin}

Les salles à manger des hôtels sont rivales des grands restaurants qui sont nés au lendemain de la Révolution française. Avant 1789, la grande cuisine, en France, se concoctait dans lès châteaux et hôtels particuliers de la classe nobilaire. Quand l'aristocratie eût la tête coupée et les goussets vidés, ses cuisiniers en chơmage s'engagèrent dans wl'hostelleriew ou fondèrent des établissements destinés ả faire goûter aux bourgeois, moyennant un écot individuel qui couvrait les dépenses et assurait un bénéfice raisonnable, les plaisirs gustatifs des anciens dictateurs.

On nomma ces établissements des urestaurantsw, proprement, des endroits oủ l'on se restaure, oủ l'on refait ses forces. L'entreprise a eu du succès. Elle a essaimé par la ville et en province. Certains restaurants connurent une renommée étendue et de grands chefs s'y sont faits une réputation importante. On afficha des menus de table d'hôte à prix fixe, ou des menus à la carte a prix variable. La clientèle était oủ bien sédentaire et urbaine ou bien nomade: autochtones et étrangers. La cuisine qu'on y pratiquait avait ses traditions et ses créations, tributaires des cultures locales ou du calendrier agricole du pays. La grande cuisine française est née de ces pratiques personnelles et régionales.

L'hôtellerie a donc hérité d'une cuisine de qualité et l'hôtellerie internationale a adopté la grande cuisine française et quelques plats d'autres cuisines nationales. Mais ces plats ont été adaptés, par besoin de standardisation et de rentabilité. Puis, I'hötellerie les a fait connaître en se multipliant. Le coq au viń, les couscous, les pâtes, les paellas sont des plats standards que le touriste reconnaîtra facilement, auxquels il se sera habitué et s'accrochera. Ainsi, le touriste est protégé contre le risque le plus menacant du voyage: manger.

II s'est donc développé une gastronomie internationale d'hôtel, qui suit les mèmes tendances que l'industrie touristique: stan= dardiser ses produits, sécuriser le touriste, le divertir, lui donner le sentiment qu'ailleurs il est tout de même proche de chez lui et qu'il peut vivre à l'aise les rêves et les fantasmes que les industries dont il a acheté les produits lui ont fabriqués.

Confortablement attablé sur une terrasse attenante à sa chambre et dominant des cataractes impressionnantes, ce couple de touristes, redevenu amoureux, prolongera dans la brise du soir et le mol balancement des palmiers sous la lune, un repas fin, exotique, arrosé d'un vin capiteux qu'on vient de verser discrètement dans leurs verres qui s'élèvent lentement entre deux regards échangés, émus par la passion de la béatitude. Caméra!

\section{La nature et la culture, homogénéisées!}

N'importe quel lieu touristique n'est plus aujourd'hui qu'à quelques heures de vol, mais plus aucun n'a de secret. Le voyageur d'aujourd'hui, aussi loin qu'il le souhaite, peut tout voir, tout goûter et se divertir de tout ce qu'on aura imaginé de lui aménager et de lui vendre.

A travers les pays hôtes, et avec leur complicité d'ailleurs, car plusieurs ne tiennent pas a se faire connaître trop intimement (le tourisme ca paye, mais ca dérange aussi), des couloirs panoramiques, des installations hôtelières et vacancières, des menus spéciaux sont réservés aux touristes, en marge des réalités culturelles, sociales et politiques réelles.

Mais, le tourisme en récupere l'essentiel qu'il trie et qu'il traite pour en faire des attractions exotiques qui feront voyager des foules. Car pour le tourisme et ses industries auxiliaires, un pays, une nation, une culture se réduit à une collection d'essences nationales faite de monuments et de sites, de spectacles costumés et d'artisanat folklorisé, de quelques valeurs culinaires gastronomisées. Bref, une typologie de repéres banalisés qui permet de constituer un discours illustré, commercialisé, rentable et sans cesse recommencé.

Cette industrie, à l'instar de l'Industrie, a dompté à sa manière la Nature: elle en a fait une attraction aménagée. Elle a aussi dompté la Culture, en la banalisant. Paradoxalement, c'est en nous rapprochant de l'une et de l'autre qu'elle nous en a éloigné. Et ce qui était opposé, fondamentalement, Nature et Culture, a été par elle homogénéisé.

Voilà un autre résultat de la culture industrielle, la cultre quantitative, la culture de masse, la culture du profit. C'est une culture nouvelle qui anihile l'entreprise individuelle, les particularités singulières, et privilégie les activités de groupe et le pluriel uniformisé. On peut tout voir, il faut tout voir! Mais tout est rien. Et dans cette tentative de tout voir, I'unique nous échappe. L'unique, c'est soi-même. C'est le voyage extérieur, le voyage d'Urien.

\section{Le repas d'Urien}

"Le repas est /"achevement d'un dispo. sitif destine a attirer un fragment du monde a des fins d'analyse et d'appropriation".

Frédéric Lange ${ }^{|14|}$

\section{La grande table}

La gastronomie est une activité ludique. C'est la fonction alimentaire portée à son niveau de jouissance le plus gratuit et le plus raffiné; et la maîtrise culinaire élevée au rang de l'art. Elle est associée aux repas fastueux et à une oeuvre culinaire de grande classe. Aussi est-ce une activité couteuse pour le client, mais lucrative pour le patron. S'y adonnent donc les gens fortunés, pourvu qu'ils soient nantis de cette autre richesse: le temps, l'éducation et la culture, ce qui n'est pas toujours le cas, surtout chez ceux de fortune récente. On n'est pas gastronome sans quelques moyens, ni sans une certaine culture. Voilà l'élite.

\section{La petite table}

Mais pour les gens ordinaires, il peut s'agir de faire bonne chère quand on en a le loisir, car un plat simple, voire upaysano, peut être un plat gastronomique s'il est équilibré et savoureux.

Bien sûr, tous les touristes ne descendent pas au grand hôtel. Beaucoup s'arrêtent dans des hôtels de moindre envergure, de 
petits hôtels et de sympathiques pensions où l'on peut prendre des repas convenables. II y a d'autre part les restaurants de tous ordres, qui sont nombreux.

Ceci dit, il reste que l'alimentation, activité intime entre toutes, pose des problemes particuliers aux touristes.

a Le sale est dehors, la faiblesse dedans. tels sont les postulats de /thygiene modernes.

Frédéric Lange ${ }^{(15)}$

Reprenons nos postulats du début sur la Nature et la Culture.

\section{Le cru}

La première nécessité pour l'homme, la plus impérative, la plus fréquente est celle de se nourrir. Elle surgit comme une pulsion sauvage qui nout met en contact brutal avec la Nature. Or la Nature extérieure est dangereuse et la Nature intérieure menacante. Là, surtout, il a fallu déjouer la Nature, la distancier, la dompter.

L'invention de la Culture nous a permis de conjurer ces dangers et d'établir une distance protectrice salvatrice. Dans la Culture, outre les codes sociaux, entrent pour une bonne part l'invention des outils, l'élaboration des techniques dont on a vu qu'on avait multiplié la puissance au point de transformer la Nature, de la dominer et même de la menacer

\section{Le cuit}

Les premiers outils inventés furent sans doute ceux reliés à la nécessité de s'alimenter. Aussi, I'alimentaire (la Nature) s'est-il résolu dans le culinaire (la Culture). Et celuici s'est réalisé dans le repas (le code culturell.
Aussi, cette activité restauratrice est-elle celle qui de toutes les activités humaines a été le plus profondément marquée par la Culture, par les cultures. S'y est appliquée toute l'ingéniosité humaine, $s^{x} y$ est réfugié tout son imaginaire. L'onirique, le symbolique, les mythes, les fantasmes, les signes, les codes ont prévalu au choix des aliments (l'agriculture), à leur transformation (la cuisine), à leur présentation (le repas).

"Dans l'acte alimentaire, homme biologique et homme social sont étroitement, mystérieusement mêlés, intriqués. Sur cet acte, en effet, pèsent des contraintes et regulations biochimiques, thermodynamiques, métaboliques, physiologiques; pressions écologiques; mais aussi patterns socio-culturels, préferences ou aversions individuelles, représentations, systèmes de normes; codes (prescriptions et prohibitions, associations ou exc/usions), agrammaires culinairesn, qui gouvernent le choix, la préparation et la consommation des aliments..

Claude Fischler ${ }^{(16)}$

\section{Les manières de table}

Chaque pays, chaque nation, chaque culture crée son propre code alimentaire. II y a entre chaque code des différentes importantes. Si bien que la rencontre des cultures a ce niveau exige du temps, une initiation, des ménagements, des précautions. Le touriste vient lui-même d'une culture culinaire fortement codée, par laquelle toute sa socialisation s'est développée et de laquelle dépend sa sécurité profonde. son assiette fondamentale. Entrant dans un autre pays, il entre dans une autre culture culinaire tout aussi fortement codée que la sienne. Comme il passe dans ce pays, à tra-

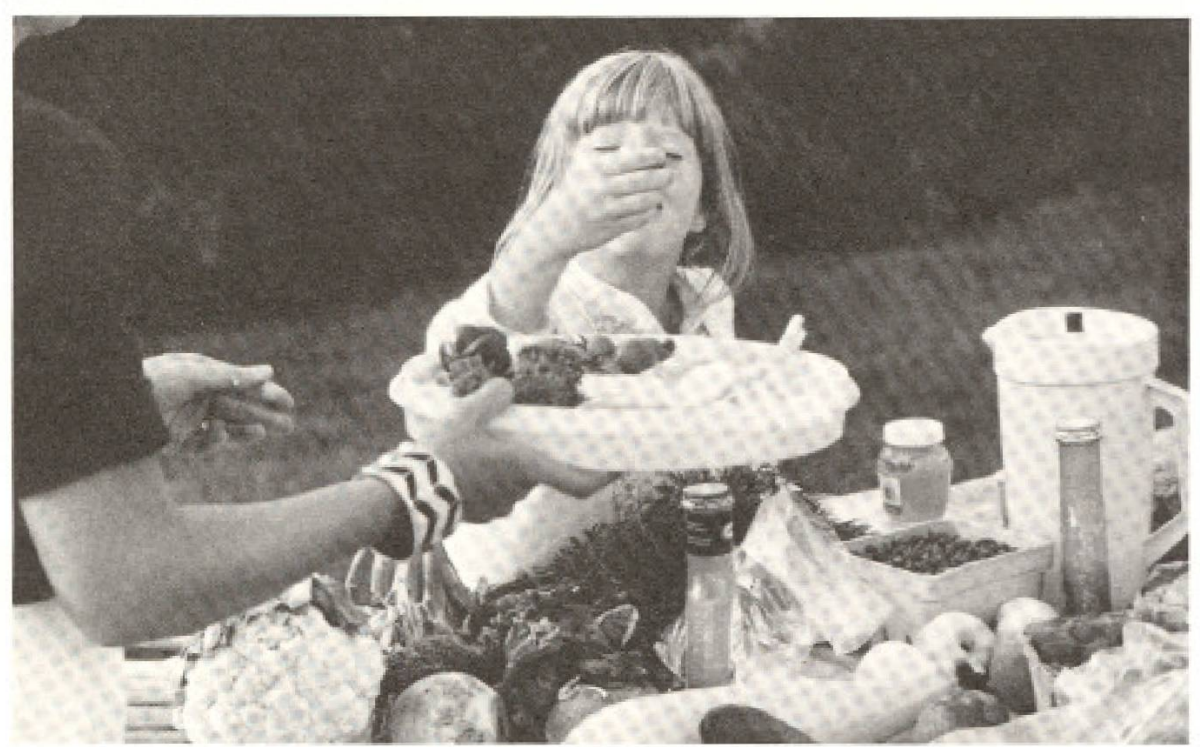

La gastronomie est une activité ludique. Pour les gens ordinaires, il peut s'agir de l'art de faire bonne chère quand on en a le loisir... un plat simple peut être un plat gastronomique s'il est équilibré et savoureux. vers ce pays, et qu'il ne s'arrête que dans ses lieux pittoresques ou ses stations vacancières, il n'a pas le temps de pénétrer dans la culture réelle du pays, dans son système culinaire. II n'en a pas le goüt non plus, au sens psychologique et physiologique. Car le goût, l'appétit, c'est aussi et surtout une affaire de culture.

"En particulier, il hi manquera, pour. sinon pénetrer ce pays, au moins en apercevoir quelque bout de réalité, ces deux truchements essentie/s: la cuisine et les femmes.

Jean Cassou ${ }^{(17)}$

\section{L'anxiété}

Or le touriste ne peut tout de même pas échapper à la pression, à la pulsion du besoin alimentaire, bien qu'il l'eutt souhaité pour toute la durée de son voyage. Ce qui aurait facilité bien des choses. Comme il a perdu ses repères culinaires personnels et culturels, que va-t-il faire? Apporter ses provisions? Certains, voire plusieurs, le font, mais partiellement. (II se trouve dans les bagages de bien des touristes nordaméricains des pots de beurre d'arachide ou des bouteilles de ketchupl) Le faire totalement est impossible. Amener son propre cuisinier? Quand un touriste était un roi ou un tsar, il le faisait!

"Manger c'est prendre le risque d'ouvri, au seul hieu du corps indemne de toute souillure, une brèche où s'engouffreraient les flux excrémentie/s.s.

Noëlle Chåtelet ${ }^{(18)}$

Donc ce qui entre dans le corps est dangereux. Qu'on pense à cet égard aux précautions auxquelles on invite le touriste pour se prémunir contre la fameuse aturistan: piqüre, comprimés, ne pas boire l'eau du pays, peler les fruits, bref, se méfier. Et comme environ $15 \%$ des touristes reviennent avec de mauvais souvenirs gastriques, on fait attention, on s'inquiète.

II n'y a aucun risque à voir, à s'amuser, à se détendre à l'étranger. Aucun ou peu à dormir dans des draps, sur des lits différents. Mais à manger et à boire ce qu'on ne connaît pas, ce qui a un autre goût, une autre forme, une autre texture, une autre odeur, une autre couleur, le risque est grand.

II $y$ a toujours une anxiété, une réticence inquiète devant une cuisine inconnue.

"Partout et toujours l'alimentation est percue dans ses rapports à la santé et a la maladie ou du moins aux idées pas toujours rationnelles que les humains se font des raisons et conditions de cette santé et maladiev.

Jacques Barrau ${ }^{(19)}$ 


\section{La sérénité}

Ce que I'on sait maintenant du touriste, sa recherche du confort et de la sécurité, le peu de capacité qu'il a pour l'aventure et surtout le peu d'occasion qu'il a d'être en prise directe avec les cultures étrangères. a la table comme ailleurs, nous font comprendre son profond malaise.

Du moins, les industries touristiques et hoteliéres ont compris cela et, pour calmer sa peur instinctive de la rencontre culturelle véritable, elles lui ont ménagé des couloirs touristiques et des abris protégés au sein des cultures mêmes.

"Partout oú $i l$ y a du junk food, Lucien Francoeur se sent dans son element. Lui qui se prétend mauvais voyageur: uje $n$ aime pas me trouver en terre inconnue: ca me rend très vulnérablen oublie toutes ses angoisses a la vue d'un Big Mac....

Danièle Rudel-Tessier (20)

Heureusement pour le touriste, d'autres industries, l'agro-alimentaire et la restauration rapide, elles aussi soumises à l'implacable loi de la rationalisation et de la rentabilité, ont rếussi â aplanir ses difficultés en créant d'un pays à l'autre, une uniformité alimentaire de plus en plus repandue. L'industrie est passée par lả aussi.

"... tout tend awjourd'hui a /homogéneisation des modes et des conduites culi. naires, le tout sur fond de ufast-foodn. de cantines, de chaines de restaurants quasi-industrielles, de rayons de plats cuisinés en conserve dans des hypermarchés..."

Jacques Barrau ${ }^{211}$

\section{L'hambourgeoisement}

En effet, dans tous les pays industrialisés, I'Industrie a provoqué des changements profonds dans les modes de vies: accélération de la vie quotidienne, séparation physique des lieux domestiques et des lieux de travail, apparition de la journée continue et des horaires controless, intégration définitive des femmes au marche du travail. Sur le plan des techniques alimentaires: apparition des mets en conserve, réfrigérés, congelés, surgelés; multiplication des cantines, naissance de la restauration rapide systématisée, nécessité de rationaliser et de contingenter la production agroalimentaire. II en est résulté, dans ces pays, une simplification radicale dans le code alimentaire et une production agroalimentaire et culinaire hautement standardisée.

Cette métamorphose industrielle, en ce domaine comme dans les autres, a sauvé le touriste d'un grand danger qui le mena- cait, le choc culturel culinaire, principal risque de son entreprise kperipatéticiennew.

II peut se gaver sans crainte. Pizzas, hotdog, big-mac et autres restaurations restauroutières industrielles pourront accomplir leur voyage intérieur sans surprises ni pour le coprs, ni pour l'esprit. C'est le repas d'Urien.

\section{Un virage dangereux}

\section{Urien écoeuré}

L'Industrie, cet épiphênoméne historique a transformé profondément les rapports de I'homme avec la Nature et avec la Culture. Dans cette transformation, il a lié dans un sort commun le tourisme, le touriste et la gastronomie. Ce qui relevait de l'art, voyager et manger, donc d'une relation personnelle avec la nature des choses, relève maintenant de l'industrie c'est-à-dire d'un système conçu pour la rentabilité et destiné au grand nombre: production de quantite et consommation de masse, avec des profits a la clé. Cette machine est un véritable rouleau compresseur des cultures individuelles, régionales, nationales, ce qui a une incidence fatale pour le tourisme et la gastronomie.

"Il y a la une exploitation ehonted du desarroi alimentaire de l'heure et, souvent tentative dehberée d'ethnocide gas. tronomique au service de Timperialisme économiquen.

Jacques Barrau 221

II $y$ a dans ce résultat quelque chose de fatal, un virage technologique et culturel dont on déplore les conséquences pour les cultures traditionnelles et qui génère de grandes incertitudes pour l'avenir.

"En fait nous wivons probablement dans ce domaine une perriode chamiere ou une vision rationnelle technicienne lau sens oú le XXe siecle créa dans ce domaine la siennel de la fonction de nourriture a du mal a se formuler entre des habitudes anciennes inadaptées desomais auX conditions quiprévalent et une nouvelle conception du manger; celle-ci nows desole, meme s'il est probable que la né- restauration actuelle $n$ 'a pas encore formule definitivement le style qui caracterisera la nutrition des prochaines décennies, mais chacun la pressent comme inévitable: manger ne sera plus un art mais une activité industrielle parmi dautres.

Meme la France qui, dans sa culture a elevé cette activité au rang d'art et lui a méme consacré ce qui mérite le quahcatif de hitterature, mëme la France donc n'échappe pas a cette régle...

Asper, Baretje et Penz $23 \%$

\section{Urien blasé}

Dans le tourisme, les mêmes craintes sont formulées envers ce qui apparaît comme une déviation â l'égard de la Nature, de la Culture et de l'Histoire.

aL 'essentiel du tourisme (...) n 'est et ne saurait etre que dans /"epanouissement culturel de /homme, que dans /enrichissement et l'apaisement des esprits, que dans la naissance d'une connaissance phus exacte ef phus vaste du monde, et par lá mème, dans une fraternisation active a l'echelon des peuples de la planéte. Sile tourisme ne devait pas de toutes ses forces, de toute la volonte de ses dirigeants, de ses cadres, de ses inspirateurs, servir fondamentalement, foncièrement la poursuite de tels objectifs, il ne serait plus que la caricature de luimeme. /I deviendrait une industrie comme une autre, a ceci prés qu'elle serait basée sur une odieuse mystification, sur un détoumement deliberé des meilleures chances de lhomme modeme au bebéfice de ses seules balances de comptes, au profit de ses seuls bilans materiels et venaux.

... I'enveloppe économique n'est rien si elle ne recouvre un fruit de haute saveur culturelle, de profonde signification morale et humaine.

Arthur Haulot ${ }^{\mid 241}$

\section{Virage contrôlé}

On le voit, nous sommes conviess a la vigilance, a la diligence dans ces domaines comme dans d'autres, à garder ferme les mains à la barre et à effectuer un virage contrôlé si nous ne voulons pas connaitre la déroute totale et une issue fatale de notre Nature, de notre Culture et de notre Histoire.

Revenons à notre question premiere; le tourisme peut-il intégrer la gastronomie a ses ressources. Pour ce faire, il faut que le tourisme se ressaisisse et cesse de traiter ses ressources comme il l'a fait jusqu'à présent; qu'il retrouve ses objectifs premiers, celui du vrai voyageur, sans renier pour autant ce qu'il a acquis de positif pour ce dernier.

Quant a la gastronomie, si l'on veut qu'elle soit une valeur culturelle au bénéfice du tourisme et du touriste, il lui faut revenir á ses sources, la convivialité, la variété, la saveur, la fantaisie, le plaisir. 


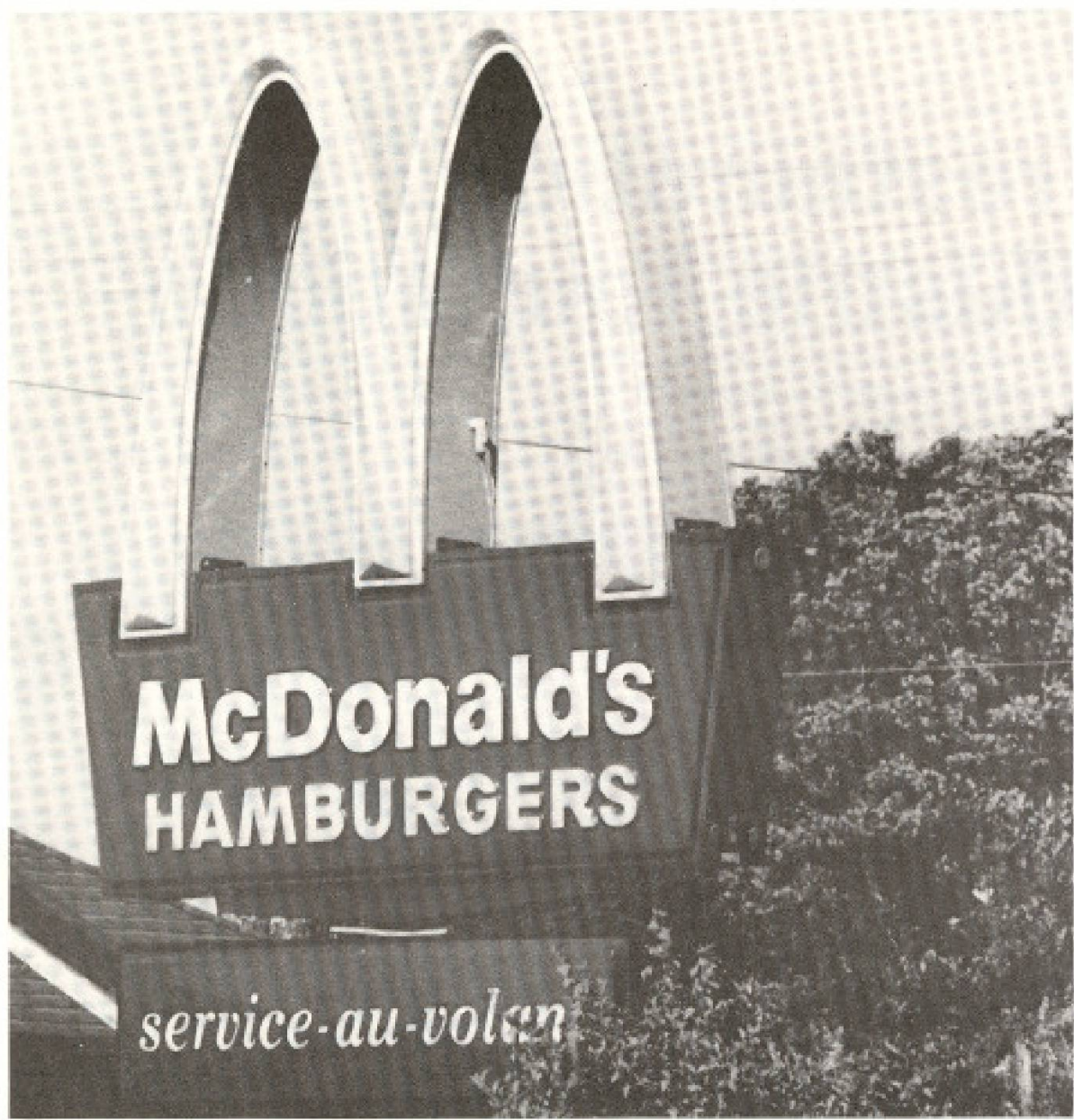

On peut se gaver sans crainte. Pizzas, hot-dog, big-mac et autres restaurations restauroutières industrielles pourront accomplir leur voyage intérieur sans surprises ni pour le corps, ni pour l'esprit...

"Le tourisme, a moins de devenir /'art des troupeaux mouvants, se doit de demeurer le fruit de la fantaisie, du gout personnel, de la decouverte, le produit d'une aspination individuelle, libre et depourvue de trop de ca/cul $\mu$

Arthur Haulot ${ }^{125}$

Ces mêmes qualités prévalent aussi pour la gastronomie, ce lieu privilégié des rencontres entre les hommes et les sociétés.

ues hommes, les societes quils for. ment, leurs crilisations, se sont faits eux-mêmes, et cela par une maitrise croissante de la nature à des fins qui furent initialement alimentaires. Dans ce processus, la recherche du plaisir gusta. tif a eu, jen suis convaincu un rôle primordial Ne renonçons pas à cette recherche essentielle, a la qualité de nos viesn.

Jacques Barrau $126 i$

\section{Le nouvel Ulysse}

Au fond, devant la massification nivelante, ce qu'il faut libérer c'est I'individu, stimu-
Au fond, si ces deux activités ludiques ont été liêes au même sort de la dénaturation par I'Industrie, c'est qu'elles avaient des affinités profondes. Elles peuvent s'en sortir en s'épaulant mutuellement et à elles deux, sauver le touriste et les cultures.

Car, de même qu'ill n'y a pas de tourisme et de gastronomie sans culture, de même il n'y a pas de culture sans tourisme ni sans gastronomie.

En tout cas, il faut que cette dernière activite, fondamentale, mère de toute industrie et de toute culture, puisse continuer de mettre au monde l'Homme, ses cultures et ses civilisations dans une Nature qui ne révêle ses secrets et ne dispense ses bienfaits qu'apres une contemplation respectueuse et réfléchie.

\section{Références}

(1) BRAUDEL, Fernand, Alimentation et catdego ries de l'histoire, 1961, cité par Jicques Barrau.

(2) BACHELARD, Gaston, La terre et les röveries de la volonte, Paris, Jost Corti, 1948.

(3) PLUTAROUE, Le banquet des sept songes, cite par Frederic Lange, page 78 .

(4) BARRAU, Jacques, Les hommes et leurs aliments. Paris. Messidor/Temps Actuels. 1983. page 368

(5) LANGE, Fredencic, Manger ou les jeux of les creux du plat. Paris, Seuil, 1975, page 85.

(6) LANGE, Frederic, Idem, page 94.

17) FISCHLER, Claude, Presentation, in Communications 431 . Paris, Seuil. 1979. pages 1 a 3 .

(8) RENAN. Ernest, Souvonirs d'Enfance et de Jeunesse. WPriàne sur I'Acropoles, Paris, Calman-Levy

(9) DU BELLAY, Joachim, Regrets, $X \times X$

(10) DE VIGNY, Afred, Les destindes, oLa Mason du bergers.

(11) CASSOU, Jean, Du vorage au towrisme, in Communications 28. tut que pour trois ou cing semaines par année, le devienne à l'année longue. On ne sait pas ce que l'Industrie nous prépare, en diminuant le travail et en allongeant les vacances. II est possible aussi qu'en standardisant tout, l'Industrie ait forgé les techniques qui lui permettront de créer du singulier, du particulier, de la variété et de suivre les caprices de l'imagination et les méandres de la création, facilement, souplement. On le prévoit déjà avec les nouvelles générations d'ordinateurs.. Cela générera une Culture nouvelle quil nous fera regarder comme barbare cette époque où tout était standardisé.

Toute initiative pour le recouvrement des valeurs gastronomiques, le développement de sa variété et son acessibilité partout et à tous ne pourra qu'enrichir le tourisme. De même, une attention respectueuse du tourisme à l'égard des cultures régionales ne pourra que permettre la connaissance et la recherche du contact culturel authentique que suppose l'activité gastronomique. II ne suffira plus de voir. II faudra aussi gouter.
[12] CASSOU, Jean, lbidem.

(13) BAUDELAIRE, Charles, Les fleurs du mal, LII, allinvitation as voyages.

(14) LANGE, Frederic, Idem, page 34.

‘15] LANGE, Fredéric, lidem, page 86

[16) FISCHLER, Claude. Ibidem

[17) CASSOU, Jean, Idem, page 29

(18) CHÁTELET, Noelle, Le corps a corps culinalire, Paris, Seuil, 1977, page 28.

I19I BARRAU, Jacques, Idem, page 28

Doi FUDEL-TESSIER, Dande, Francoeus $Z$ e roc ker, in L'actualite, Montrial, Vol 9 , no 9 , sep tembre 1984, page 118 .

(21) BARAAU, Jacques, Idem. page 347

(22) BARRAU, Jacques, Idem, page 363

(23) ASPER, 5, BARET.JE, R. PENZ, F, Tourisme restauration - Essai bibliographique, Essai H39, Aix-en-Prowence, Centre des hautes btudes tou ristiques, 1978, Introduction.

241 HAULOT, Arthur, Un certain tourisme, Mons, Foddration du tourisme de la province de Hai-

(25) HAULOT. Arthur, Idem, page 11

[26! BARRAU, Jacques, Idem, page 369 nault, 1989, page 90. 